to political science education through information technology, as well as a copy of the nominee's curriculum vitae to APSA, attention Theresa Gubicza.

The letter of nomination should explain how the nominee has addressed at least one pedagogical problem fundamental to the discipline; provided an innovative solution offering clear advantage over other techniques and demonstrated substantial impact on improved student learning. The awards are made to individuals and can be granted for any aspect of information technology. The program is limited to applications used by undergraduate students.

\section{Anticipate Travel Funds for IPSA World Congress}

APSA has applied to the National Science Foundation for funding that would allow political scientists to travel to the International Political Science Association's World Congress to be held in Seoul, August 17-21, 1997. Should funds become available, preference will be given to APSA members delivering papers at the World Congress. Funding will be targeted to young scholars, faculty members below the rank of full professor, and those who have not previously participated in an international meeting. Individuals who received NSF-supported travel grants to the 1994 World Congress in Berlin will not be eligible for travel support in 1997. APSA will publicize the availability of these funds if they are granted by NSF.

\section{Computerized APSR: Research at Your Fingertips}

Bother no more with lugging old volumes from dusty stacks. Research in political science is significantly easier with newly established computerized access to the American Political Science Review. Last year APSR joined JSTOR, a collaboration of 45 journals in 11 disciplines ranging from history to economics to philosophy and Asian studies. Beginning in January, all volumes of APSR published between 1906 and
1992 were made available to universities and colleges throughout the United States, and the growing number of institutions purchasing JSTOR should include all major American research institutions within a few years. Each year, the volume of $A P S R$ published five years previously becomes available on JSTOR.

For information on participating institutions and titles listed through JSTOR, access their website at http://www.jstor.org.

\section{Survey Finds $23 \%$ Acceptance Rate Among Political Science Journals}

The average manuscript acceptance rate is $23 \%$ among 103 political science journals recently surveyed. The survey was conducted by Fenton Martin and Robert Goehlert, the Indiana University Librarians who prepared the fourth edition of Getting Published in Political Science Journals: A Guide for Authors, Editors and Librarians. This 1997 APSA publication summarizes the findings of the survey conducted by Martin and Goehlert and provides a guide to help political scientists select appropriate journals for their work.

While journals' review procedures vary considerably, Martin and Goehlert find that the main reason that manuscripts are rejected during initial screening is that the subject matter is inappropriate to the journal. Once an article has been accepted for review, an author can generally expect to wait two and a half to three months to hear whether the manuscript has been accepted, has been rejected, or needs revisions. Then typically another 11 months expire before publication.

Contrary to popular belief, most journals do not have substantial backlogs of accepted articles, according to Martin and Goehlert. Moreover, approximately one-third of the journals surveyed reported that they solicit over $10 \%$ of their articles.

Getting Published in Political Science separately lists each journal surveyed and provides a wealth of information on each journal's guidelines and policies, including types of articles sought, acceptance rate, style requirements, proper length of articles, and information on how and to whom to submit manuscripts. Martin and Goehlert provide several pages of suggestions on how to identify appropriate journals to which particular manuscripts might be submitted and on how to prepare articles for publication.

Because there is no predominant style for political science journals and requirements vary, political scientists seeking publication of their work can be greatly assisted by Goehlert and Martin's new guide which contains $30 \%$ more listings that the third edition, published under the title Political Science Journal Information. This work is also intended for librarians, editors and anyone interested in refereed journal publication in political science, and can be obtained by calling the APSA National Office at (202) 483-2512. See also the advertisement in this issue of $P S$.

\section{APSA Helps Plan Part-Time Faculty Conference}

APSA has become an active participant in planning a conference on part-time faculty to be held in the fall of 1997. The purpose of the conference will be to provide data on the use of part-time faculty and to consider its impact on educational quality. The conference is likely to consider issues such as the appropriate treatment of part-time faculty, including salary and benefits, office space, library privileges, and related matters. Other topics may include the increased responsibilities of fulltime professors that result from hiring a larger portion of temporary teachers and the effect of such increases on the teaching of students and the quality of the curriculum.

Barbara Ramusack of the University of Cincinnati chairs the planning committee and represents the American Historical Association which initiated the idea of the conference. Other organizations involved include the American Association of University Professors, the American Council of Learned Societies, the American Mathematical Society, the Modern Language Association, the American Sociological Association, 


\begin{tabular}{|c|c|c|c|c|c|c|c|c|c|c|c|}
\hline & $\begin{array}{c}\text { All Faculty } \\
\text { and } \\
\text { Graduate } \\
\text { Assistants }\end{array}$ & $\begin{array}{l}\text { Number } \\
\text { Full-Time } \\
\text { Faculty }\end{array}$ & $\% \mathrm{~F}-\mathrm{T}$ & $\begin{array}{c}\text { Number } \\
\text { With } \\
\text { Tenure } \\
\end{array}$ & $\begin{array}{c}\% \\
\text { Tenure } \\
\end{array}$ & $\begin{array}{c}\text { Number } \\
\text { on } \\
\text { Tenure } \\
\text { Track }\end{array}$ & $\begin{array}{c}\% \text { on } \\
\mathrm{T}-\mathrm{T}\end{array}$ & $\begin{array}{c}\text { Number } \\
\text { Part-Time }\end{array}$ & $\% \mathrm{P}-\mathrm{T}$ & $\begin{array}{c}\text { Number } \\
\text { Grad. } \\
\text { Assists. }\end{array}$ & $\begin{array}{c}\% \mathrm{G} \\
\text { As } \\
\end{array}$ \\
\hline$\overline{\text { All }}$ & $1,118,293$ & 545,706 & $48.8 \%$ & 279,424 & $25.0 \%$ & 114,278 & $10.2 \%$ & 369,768 & $33.1 \%$ & 202,819 & $18.1 \%$ \\
\hline Two-Year & 292,213 & 103,992 & $35.6 \%$ & 48,809 & $16.7 \%$ & 12,940 & $4.4 \%$ & 185,198 & $63.4 \%$ & 3,023 & $1.0 \%$ \\
\hline
\end{tabular}

Based on a draft version of "Fall Staff in Postsecondary Institutions, 1993," National Center for Education Statistics; April, 1996, Tables B1a, 2a, $3 \mathrm{a}$ and $\mathrm{B} 7 \mathrm{a}, 7 \mathrm{~b}, 7 \mathrm{c}$. There are small inconsistencies in the data due to differences in the component sources and the omission of about 10,000 faculty in for-profit institutions from the public and independent categories.

the National Academy of Sciences, and the Council of Graduate Schools.

Table 1 shows the percentage of faculty who are full-time professors (tenured and on tenure-track), parttime professors, and graduate assistants for 1993 arranged by type of institution. While these are preliminary figures, they do indicate that about half of professors are fulltime, about one-third are part-time, and about one-fifth are graduate assistants. These figures vary considerably across institutions.

The use of non-tenure track faculty takes on heightened importance in the wake of budgetary constraints of colleges and universities across the nation and the questioning of tenure that is occurring throughout the U.S. APSA members who have suggestions for possible topics and perspectives for the conference should contact Catherine Rudder at rudder@apsa.com or1527 New Hampshire Avenue, NW, Washington, DC 20036-1206.

\section{APSA-Online}

The APSA recently signed a collaborative agreement with H-Net, Humanities Online, to assist the Association in the development of Internet-related resources for political scientists. The partnership will allow the Association to transform its web site, APSANet, into a fully interactive political science clearinghouse. Through APSANet, Association members will be able to renew their membership, register for the annual meeting or order the latest publications. Additionally, visitors will have access to a collection of resource databases assembled by both APSA and $\mathrm{H}-\mathrm{Net}$, including upcoming conferences, fellowship opportunities, political science journals, research resources, and a host of others, all searchable through use of the H-Net search engine. The site will also soon feature access to the APSA Annual Meeting preliminary program, the APSR Index, 1969-1995, and a collection of resources for teachers and graduate students.

A second component of the agreement will allow for the development of a series of subfield-oriented e-mail discussion lists. Co-sponsored by the Association and its Organized
Sections, these scholarly lists will be devoted to research and teaching in the discipline. Each Section will have the opportunity to launch a list or series of discussion lists, with focus on their general area of study. These public lists will be open to a wide range of scholarly communities. Each list will be overseen by an editorial board and volunteer editors who serve as list moderators. At the time of this publication the first series of discussion lists should be active.

Established in 1993, H-Net is an international collaboration designed to assist humanities scholars and

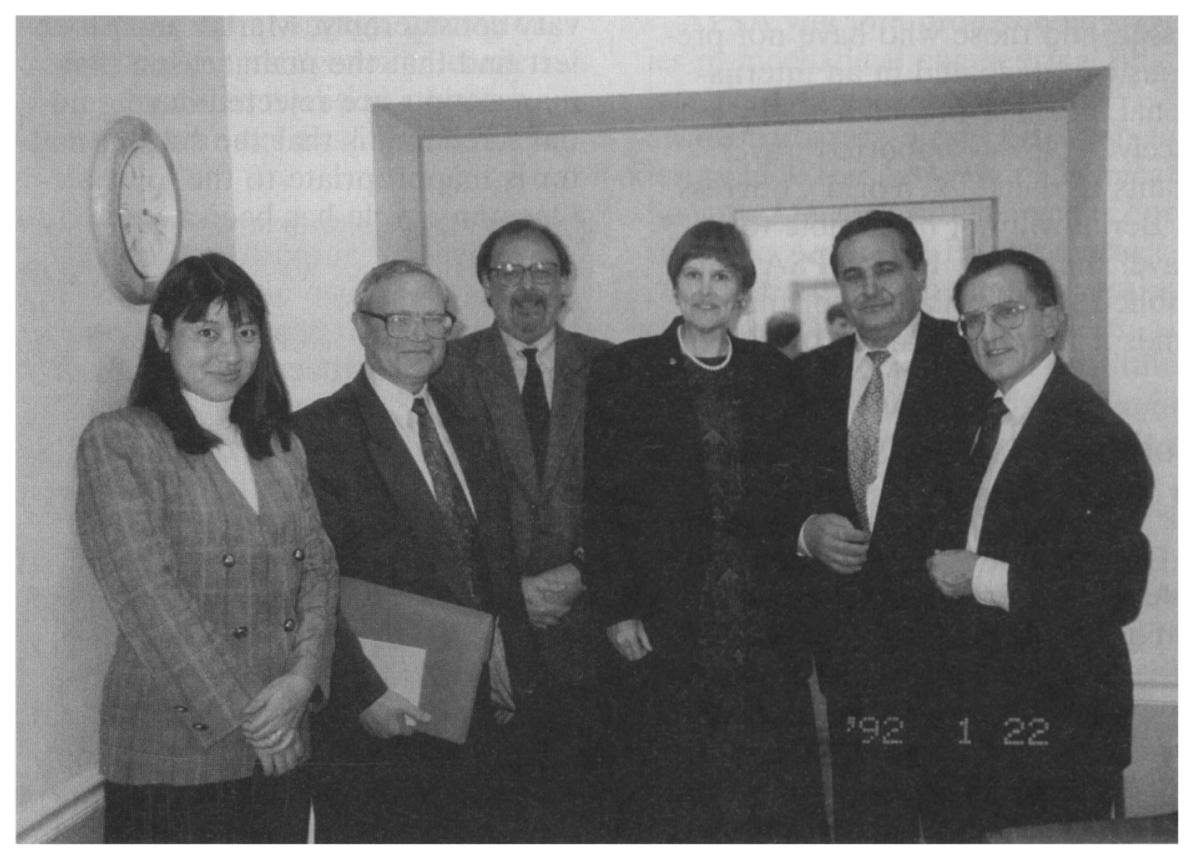

APSA and Ukrainian colleagues meet at the National Office in October. The Meeting included (L-R), Jun Yin, APSA Program Officer; Mykola I. Mykhalchencko; Robert Hauck, APSA Deputy Director; Catherine E. Rudder, APSA Executive Director; Eugene K. Marchuk; and Victor Basiuk. 